\title{
Adolescência, crise e atenção psicossocial: perspectivas a partir da obra de René Kaës
}

Adolescence, crisis and psychosocial care: perspectives from the work of René Kaës

Melissa Pereira', Marilene de Castilho Sá2, Lilian Miranda ${ }^{3}$

${ }^{1}$ Mestre em Saúde Pública pela Escola Nacional de Saúde Pública Sérgio Arouca da Fundação Oswaldo Cruz (ENSP/ FIOCRUZ) - Rio de Janeiro (RJ), Brasil. melissadeoliveira@gmail.com

${ }^{2}$ Doutora em Psicologia pela Universidade de São Paulo (USP) - São Paulo (SP), Brasil. Professora Pesquisadora da Fundação Oswaldo Cruz (ENSP) FIOCRUZ) - Rio de Janeiro (RJ), Brasil.

${ }^{3}$ Doutora em Saúde Coletiva pela Universidade Estadual de Campinas (UNICAMP) - Campinas (SP), Brasil. Professora Adjunta do Departamento de Psicologia da Universidade Federal Rural do Rio de Janeiro (UFRRJ) - Seropédica (RJ), Brasil.
RESUMO: Este trabalho pretende contribuir para uma discussão conceitual acerca das dimensões grupal e social da crise, bem como para os efeitos socioculturais da adolescência. A partir da obra de René Kaës, propõe-se um alargamento da noção de crise, entendendo-a como uma problemática cruzada entre individualização e 'grupalização', na medida em que seu desenrolar diz respeito à intersecção de fatores inter e intra-psíqucos, sociais e culturais. Essa compreensão evoca, do ponto de vista da intervenção, um trabalho psicossocial dos e sobre os grupos e instituições.

PALAVRAS-CHAVES: Adolescência; Crise; Psicossociologia; Atenção psicossocial.

ABSTRACT: This work aims at contributing to a conceptual discussion on the crisis' grouping and social dimensions, as well as to socio-cultural effects of adolescence. The broadening of the notion of crisis is proposed upon the work of René Kaës, being this concept understood as an intersection issue between individualization and the act of grouping, to the extent that its deployment concerns the intersection of inter and intra psycho, social and cultural factors. This understanding evokes, from the intervention standpoint, a psychosocial work from and on groups and institutions.

KEYWORDS: Social psychology; Crisis; Adolescence; Psychosocial care. 


\section{INTRODUÇÃO}

Os movimentos de Reforma Psiquiátrica fomentam pensamentos e formas de trabalho originais que se voltam não apenas para a substituição do hospital psiquiátrico como também para a revisão de um conjunto de saberes e práticas científicas, sociais, legislativas e jurídicas, que fundamentavam a existência de um lugar de isolamento, segregação e patologização da experiência humana. Dessa maneira, suas proposiçôes não se limitam a uma simples reformulação dos serviços de saúde, mas se dirigem a um importante questionamento tanto das práticas e instituiçóes psiquiátricas como dos conceitos e saberes que lhe dâo legitimidade (AMARANTE, 2007).

Nesse contexto, as situaçóes de crise são consideradas por vários autores do campo da saúde mental como um momento ímpar e, por sua complexidade, podem colocar em xeque a estrutura sanitária e social toda vez que deflagrarem a incapacidade de respostas por parte dos serviços. A atenção a essas situações apresenta-se como um dos aspectos mais difíceis e estratégicos, na medida em que, muitas vezes, é a partir delas que se pode dar início a um processo de cuidado integral ou, ao contrário, a um circuito de internaçóes psiquiátricas. (DELL'ACQUA; MEZZINA, 1991; AMARANTE, 2007; VASCONCELOS, 2010).

Há uma aposta da Reforma Psiquiátrica Brasileira na atenção às pessoas em momento de crise que se baseia numa lógica comunitária, que ganha um colorido intersetorial por meio da rede de serviços substitutivos ao modelo manicomial, lógica essa que deve compreender serviços de saúde em geral, assim como outros recursos da comunidade. Espera-se que a rede substitutiva tenha mais êxito em favorecer um trabalho recíproco entre serviços, criando condições para a implementação de projetos terapêuticos calcados no acolhimento e autonomia do sujeito, bem como na ampliação de suas relaçôes com seu território de vida (DELL'ACQUA; MEZZINA, 1991; AMARANTE, 2007; VASCONCELOS, 2010).

Verifica-se, entretanto, pouca discussão sobre as especificidades das situaçóes de crise em saúde mental de adolescentes, seja em textos acadêmicos, documentos oficiais ou relatórios técnicos. Há, ainda, uma defasagem entre as necessidades de atenção em saúde mental infanto-juvenil e a oferta de serviços capazes de responder às particularidades desse público.

Considerando que os substratos teóricos são fundamentais para a formulação das propostas clínicas e organização dos serviços, este trabalho pretende contribuir com uma discussão conceitual da noção de crise a partir das contribuiçóes do psicanalista René Kaës. A obra do autor (KAËS, 1982; 2002; 2005) sobre os processos grupais permite refletir sobre as articulaçóes existentes entre processos psíquicos subjetivos, intersubjetivos e construçóes coletivas e sociais, mostrando-se particularmente útil para a compreensão dos vínculos que ligam os sujeitos entre si, entre grupos e entre grupos e organizações.

Uma ressalva inicial se faz necessária sobre a discussão acerca da assistência a adolescentes em situação de crise psicossocial, i.e., requer uma ponderação, ainda que rápida, relativa à própria noção de adolescência. Como se sabe, para alguns autores, assim como a infância, a adolescência é um conceito social e historicamente construído, com finalidades específicas, dentre as quais está a possibilidade de controlar e disciplinarizar pessoas de certa faixa etária, qualificando-as para o mercado consumidor e para a vida competitiva (ARIÈS, 1981; NAKAMURA, 2009; VINCENTIN, 2006). Partindo desse pressuposto, inicia-se este trabalho pontuando que o mais importante não é um questionamento sobre o que é a adolescência, mas a consideração de que há sobre ela uma importante produção de enunciados em nossa cultura.

\section{UMA PERSPECTIVA PSICOSSOCIAL DA CRISE: AS CONTRIBUIÇÕES DE RENÉ KAËS}

A noção de crise pode remeter a aspectos sociais, históricos, familiares e pessoais e, mesmo no campo específico da saúde mental, encontram-se diferentes caracterizaçóes desse conceito advindas de diferentes teorias (DELL'ACQUA; MEZZINA, 1991; FERIGATO et al., 2007). Neste trabalho, a fim de um maior aprofundamento da reflexão sobre a crise, recorre-se 
às construçôes do psicanalista francês René Kaës, cuja principal contribuição consiste na recusa à reduçấo da crise a um fenômeno individual e na ampliação da sua conceituação, envolvendo dimensões que vão além do sujeito e do singular e lançando luzes para os aspectos grupais, culturais e subjetivos inerentes às vivências de desorganização.

Kaës (1982) explicita que, para a Psicanálise, a crise e suas elaboraçóes permanentes constituem aquisições que se aproximam da especificidade do modo de existência da psique humana. Para o autor, apesar de se tomar a crise como o que surpreende, ela não se caracteriza, de fato, pela novidade. A crise apareceria, sim, imprevistamente e seria marcada por um caráter único e singular, mas suas causas e origens assim como sua solução estariam desenhadas na história passada e nas recordaçóes. Histórias e recordações que têm no grupal sua base, sua gênese, também encontram nele a solução para a crise.

Baseado em E. Morin (1976 apud KAËS, 1982), Kaës propõe que o aparato psíquico se organiza sob a lógica de múltiplos apoios psíquicos, de forma que a falha de um deles tem como consequência variaçóes qualitativas na formação. Tal formação se dá por meio de movimentos de construção-e-destruição, de abertura-e-fechamento, de crise e criação do psiquismo, movimentos que exigem estruturas relativamente estáveis e semiaberturas entre esses suportes que se inter-relacionam por uma lei de composição. Nessa concepção, o aparato psíquico se estrutura como um sistema que convoca a ideia de antagonismo, de processos de desorganização e desintegração simultâneos ao de reorganização, de maneira que seria esse antagonismo o garantidor da constância do sistema, já que a estabilidade representaria a morte.

Nessa perspectiva, a crise é considerada por Kaës (1982) como inevitável e enriquecedora do sistema psíquico, fonte de desorganização e fonte de reorganização evolutiva. Assim, o autor sublinha a ambiguidade da crise a partir do fato de que ela libera simultaneamente forças de morte e regeneraçáo de tal modo que, ao mesmo tempo em que a destrutividade em ação aprofunda a crise - já que envolve forças de desordem, deslocamento e desintegração -, ocorre também o despertar de uma ativa criatividade. Kaës (1982) considera, a partir de Morin (1976), que a crise é 'dialetização', que sua incerteza e ambiguidade determinam seu caráter aleatório, regressivo e progressivo, mas revelam os antagonismos fundamentais, o avanço oculto de novas realidades. A crise póe em funcionamento tudo que pode proporcionar mudança, transformação e evolução.

Mais do que isso, Kaës (1982) entende que o sujeito, já ao nascer, é inaugurado pela crise a partir de uma ruptura primeira na estabilidade do aparato psíquico. A vivência de tal ruptura se dá num esquema específico que, baseando-se em Bleger, Kaës denomina de enquadre. Este funda o sentimento de segurança e, inicialmente, é constituído pelo meio que circunda o ser, geralmente representado pela figura materna. O enquadre é considerado por Bleger (1982 apud KAËS, 1982) como a organização mais primitiva e menos diferenciada da personalidade. É o elemento de fusão eu-corpo-mundo" de cuja mutabilidade dependem a formação, a existência, a diferenciação do eu, do objeto, da imagem do corpo, do corpo, da mente etc. A debilidade, própria a qualquer enquadre, leva o sujeito a procurar outras modalidades de apoio, que, paulatinamente, o vai diferenciando e afastando desse meio e ampliando seu campo de relaçóes. Esse movimento representaria o crescimento.

Nessa perspectiva, importantes momentos de vida, como as crises do crescimento próprias à adolescência, meia idade e entrada na velhice, só podem ser elaboradas e superadas pelas propriedades conjuntas da atividade intrapsíquica, do enquadre e do entorno psicossocial. (KAËS, 1982).

Kaës (1982) entende a adolescência como marcada por um momento de perda de objetos internos e externos, perda de um código social e construção de outros códigos e estruturas para as relaçóes intersubjetivas. $\mathrm{O}$ abandono do código anterior implica uma ruptura de laços e significaçóes que asseguravam, até entẫo, um modelo de condutas estáveis. A desagregação temporária é também desagregação social, podendo ser vivida como ameaça e perda de estabilidade psicológica e social, uma des-orientação, mas que comporta também a possibilidade de criação de novos códigos. Consequentemente, a adolescência traz em si a potência de inventividade e mudança. 
Para Kaës (1982) esse momento pode ser marcado por profundas angústias ou por criatividade que não afetam apenas o adolescente. A adolescência aponta para uma crise que pode encontrar ou reativar a crise da geração anterior, como a dos pais, tios, professores, que frequentemente encontram-se enfrentando suas próprias rupturas, como a entrada na meia idade, por exemplo. Ela pode suscitar uma crise nas instituições, como lares abrigados, escolas, clubes, associaçóes, instituiçóes de cumprimento de medidas sócio-educativas, igrejas. E, não se pode esquecer, a adolescência se encontra, também, no contexto de uma crise da sociedade, dos valores e regras em constante transformação.

Dessa maneira, o autor convida a pensar a adolescência como um momento de crise não focal ou individual, mas como algo dinâmico e relacional, no qual estão em jogo relações grupais, familiares, sociais e culturais. A crise do adolescente, sua interpretação pelos demais e suas repercussóes estarão sempre atravessadas por esse jogo de relaçóes. Nesse sentido, pode-se falar em "adolescências", justamente porque esse aspecto relacional dirige a diferentes formas - influenciadas pela diversidade de arranjos sociais, culturais, econômicos, intersubjetivos e históricos - de se entender, lidar e mesmo viver esse momento.

Essa é uma ponderação que se faz necessária, principalmente se for considerado, com Takeuti (2002), que, na realidade brasileira, as "tramas existenciais" juvenis de um grande segmento se confrontam com um impasse sócio-histórico de invalidação e relegação. Fala-se aqui de adolescentes com insuficiente acesso aos recursos sociais e importante privação material. Em um país marcado por tamanha desigualdade e tamanha diversidade, é preciso avaliar os diferentes jogos de relações que envolvem a adolescência das periferias pobres urbanas, dos meios rurais, das classes médias, das ruas, entre tantos outros contextos. Trata-se de nuances e meandros das relaçóes culturais e sociais, mas também familiares e grupais que marcam as especificidades da adolescência para cada sujeito e realidade.

Neste artigo, propóe-se refletir sobre a vivência da adolescência marcada, simultaneamente, pela inevitável crise, tal como definida por Kaës (1982), mas também por uma dinâmica psicossocial caracterizada pelo sofrimento extremo. Sofrimento este que, em geral, tende a interromper o potencial criador da crise da adolescência, dando lugar a um quadro dominado pela desestabilização, como é o caso da crise de sujeitos que precisam de um tratamento em saúde mental. Assim, na tentativa de superar a classificação nosográfica clássica, a partir das proposiçóes de Kaës (1982), podem-se entender como crise psicossocial aquelas situaçóes que trazem como central o "sofrimento psíquico grave", que desestabiliza diversas dimensóes da vida do adolescente, como a subjetiva, familiar, institucional e social.

\section{PENSANDO UM ENQUADRE PARA A CRISE A PARTIR DA REDE DE SERVIÇOS SUBSTITUTIVOS}

Freud, em 1913, no seu artigo "Sobre o início do tratamento", diz que o processo analítico se dá como a partida de xadrez, na qual todo o seu desenrolar depende de como foi articulado o primeiro lance. Da mesma maneira, o primeiro contato com o serviço de saúde parece ser decisivo no atendimento à crise. A forma como a crise será manejada pode direcionar todos os demais desdobramentos do projeto terapêutico e das possibilidades de intervenção junto a esses adolescentes.

Alguns autores que se dedicam ao tema da crise em saúde mental têm apresentado caminhos para a construção desse cuidado por meio das noçôes de acolhimento, vínculo e responsabilidade (DIAZ, 2009; FERIGATTO et al, 2007; FRANÇA, 2005).

Para Ferigato et al. (2007), toda situação de crise exigirá uma urgência da ação. Ação que deve ser baseada fundamentalmente no suporte, o que significaria afirmar a realidade do acontecimento da crise, sustentando sua força destrutiva para que ela encontre destinos mais criativos. Este suporte implicaria, assim, a consideração da crise a partir do caráter afetivo da experiência, concedendo-se crédito ao sofrimento embutido nesse acontecimento, testemunhando-se o fato e auxiliando-se o sujeito a inscrevê-lo em sua história.

Assim, lança-se, ao serviço ou à rede de serviços que se dedique a atenção às urgências em saúde mental, o desafio de uma consideração sobre a realidade das condiçôes dos adolescentes, seus familiares e os ideais terapêuticos. Esse desafio requer a disposição na aposta 
no contato e no diálogo com o sujeito em crise, mesmo quando a comunicação parece impossibilitada e reduzida e quando os discursos parecem não ter reciprocidade (CARVALHO, 2007).

Chama-se atenção para o fato que a crise, em seu caráter dialético, apenas pode se apresentar como um fator de enriquecimento do sistema quando conta com uma sustentação psíquica grupal. Caso contrário, representa apenas ruptura, já que as tensóes do sistema psíquico e social se acentuam nesse momento. A falta de sustentação da crise pode levar à perda da integridade de si e da capacidade criadora. Isso porque, considerando o aspecto intersubjetivo da crise, Kaës (1982) a considera como ruptura de um transcurso, uma:

\section{[...] experiência de ruptura que questiona do-} lorosamente o sujeito na continuidade de si mesmo, a organização de suas identificaçóes e ideais, o emprego dos mecanismos de defesa, a coerência de sua forma pessoal de sentir, de atuar, de pensar, a confiabilidade de seus laços e pertencimento a grupos, a eficácia do código comum a todos aqueles que, como ele, pertencem a uma mesma forma de sociabilidade e cultura (KAËS, 1982, p.27).

Kaës (1982) ressalta que o desafio consiste em reunir as condições necessárias para que elementos paradoxais como ruptura e criação sejam elaborados. Esse dilema requer, em princípio, a existência e a manutenção de um enquadre, o qual póe em funcionamento a capacidade dos sujeitos de estabelecer - inventar-criar - um campo de ilusão, um espaço de transição. Graças a isso, se articulam e são explorados e fixados os novos e antigos limites, o fora e o dentro, o novo e o velho, o cheio e o vazio, a perda do código e a intrusão do código. É graças a esse enquadre que se faz possível uma saída do sistema de crise; esse é o coração da transicionalidade, noção que Kaës (1982) desenvolve em sua obra a partir das construçóes de Donald Winnicott.

O autor explica que, para Winnicott (1975 apud KAËS, 1982), o espaço transicional é construído em tempos primevos de cada sujeito por meio da mediação feita pela mãe ou por aquele(s) que ocupa(m) o lugar de cuidado entre as necessidades psíquicas e corporais da criança e o meio psíquico e social que a rodeia. É uma zona que suporta os movimentos contínuos de união e separação, de modo que a ausência do objeto possa ser paulatinamente suportada. A ausência não é definitiva e não deve ser; o desenvolvimento se dá rumo à independência, mas tem de ser um movimento relativo. Esse processo de união-separaçáo deve se dar nas condiçóes de um enquadre firme mas flexível, capaz de suscitar e de conter, para cada sujeito, os processos necessários à elaboração de rupturas críticas, de forma que ofereça condiçôes para que o sujeito conviva com espaços vazios e, logo em seguida, resgate elementos de suas antigas relações. Esse movimento de criação comporta a lógica de que o novo está sempre sustentado numa certa tradição, com a qual guarda eterna relação de diferenciação e reaproximação (KAËS, 2005).

Quando só há ruptura não há transicionalidade. O enquadre e a 'transicionalidade' são indispensáveis ao estabelecimento de jogo interpretativo ou criativo. O espaço transicional se apresenta como lugar onde se pode colocar o que é transmitido e o que não está momentaneamente disponível, mas que outros vão poder fazer funcionar por nós ao nos oferecer representaçôes. É marcado pelo que é apresentado, em termos de enquadre, do(s) sujeito(s) a outro(s) sujeito(s), sendo um espaço a ser inventado e criado por um e por outro, em um acompanhamento mútuo (KAËS, 2005). A 'transicionalidade' permite a simbolização, um dos fundamentos da vida psíquica, e funda a experiência da cultura, da herança e da criação. A economia da transicionalidade, lembra Kaës (1982), é intrapsíquica, grupal e social. Para Kaës (2005), ao articular a área transicional com o espaço cultural, Winnicott (1975 apud KAËS, 1982) permite pensar a relação entre o mundo interno e o mundo dos signos, dos ritos, dos sentidos estabelecidos em comum, sem torná-los mutuamente excludentes, mas admitindo sua intricação.

Sua hipótese central do psiquismo organizado, simultaneamente, como individual e grupal levou Kaës (1982) a outorgar um lugar determinante na transicionalidade aos jogos da grupalidade e da individualidade. Assim, o grupal e o cultural são o núcleo básico da identidade e, consequentemente, a possível sustentação 
no momento de rupturas e de crise. $\mathrm{O}$ autor se dedica a pensar a continuidade nos momentos de crise, sendo assegurada pela herança cultural e entendida como espaço potencial entre o indivíduo e seu entorno. A cultura articularia o código psíquico pessoal com o código social, de maneira que a experiência cultural seria uma extensão da ideia de fenômenos transicionais. Sai-se da crise pelo social. A história do homem dar-se-ia no "entre" crise e resolução, "entre" o social, o mental e o psíquico que, juntos, tecem o sujeito particular.

A partir de Kaës (1982), entende-se que a enfermidade 'individual' não é uma tela - entre si mesmo e o mundo hostil -, um cofre - refúgio num lugar de cuidados e reparação - ou fechamento, mas é indissociável do social e, por isso mesmo, fala da necessidade de uma estrutura social de recepção que serviria à elaboração da experiência de ruptura. Assim, vale sublinhar que o papel do grupo na resolução de uma situação individual de crise evidencia a ampliação de uma noção individualista da crise, uma dupla problemática cruzada entre individualização e grupalização, de maneira que a elaboração da crise colocaria em questão o trabalho psicossocial.

Considera-se que as proposições de Kaës podem apoiar as propostas da Reforma Psiquiátrica, direcionando para uma nova ética de atendimento à crise, a partir da qual ela é considerada como um acontecimento de ordem multifatorial, que traz à cena a interdependência de aspectos biológicos, culturais, psicológicos, sociais e culturais, não só no seu desencadeamento como na própria estruturação psíquica do sujeito que a vive. Essas construções levam a reafirmar que a atenção à crise deve se basear na rede de serviços e instituiçóes assim como na articulação com diversos recursos comunitários (DELL'ACQUA; MEZINNA, 1992).

\section{A CRISE NO E DO SERVIÇO}

O bojo dessa discussão dirige à relação entre o serviço de saúde, suas condiçóes estruturais, a dinâmica de seu funcionamento e o adolescente em crise. Sublinhando a questão da crise como multifatorial, deve-se questionar se os serviços voltados para o adolescente e a articulação entre serviços podem se apresentar hoje como lugar de enquadre para sustentaçáo da crise, tanto para o adolescente como para sua família e seu entorno social.

Para tratar dessa questão, vale esclarecer, ainda que rapidamente, que Kaës (2002) propóe que, assim como o postulado da Psicanálise se funda na hipótese de uma realidade psíquica baseada no inconsciente, a prática institucional ou de grupo não pode desconsiderar essa trama. Ao aceitar o desafio de pensar a instituição, a Psicanálise reconhece as formaçóes intersubjetivas e transubjetivas na formação do psiquismo, discutindo as nuances das formaçóes dos grupos e dos processos inconscientes envolvidos.

Nesse sentido, Kaës (2002) salienta que a crise questiona a instituiçấo e, neste caso, as instituiçóes assistenciais como um todo, pois, ao desagregarem os contratos, pactos, consensos e acordos inconscientes os evidencia, exigindo, consequentemente, uma análise multifocal. Essa contribuição do autor é central à avaliação da relação entre profissionais, equipes e serviços na atenção ao adolescente em crise. Deve-se pensar o quanto a crise do adolescente, entendida como forte sofrimento psíquico, mas também incluindo a própria adolescência como momento de construçóes e desconstruções envolvendo um jogo de relaçôes, pode desestabilizar os serviços e instaurar uma nova crise: a das instituições envolvidas.

A partir dessa concepção, a crise vivenciada pelo adolescente anuncia elementos críticos dos serviços, que, se náo forem reconhecidos e tratados, podem facilitar que a crise perca seu potencial criador e se configure apenas como desestabilização e grave sofrimento para o sujeito, a família, seus grupos e para os profissionais envolvidos na atenção psicossocial.

Nas palavras do autor, é necessário "considerar-se ainda que a instituição é o lugar de uma dupla relação: do sujeito singular com a instituiçấo e do conjunto de sujeitos vinculados pela e na instituição. Por isso, toda emergência psíquica possui a priori um valor de sintoma significativo para o conjunto institucional." (KAËS, 2002, p.20).

Essa ideia reforça a necessidade de que o próprio serviço conte com apoio para a sustentação e elaboração das crises, já que são sempre vividas no espaço de intersecção entre a 'grupalidade' formada pela equipe, os 
sujeitos usuários e todo o entorno sociocultural e familiar em que se colocam. Tal apoio pode advir da supervisão clínico-institucional e dos recursos concretos do sistema de saúde, mas também deve ser protagonizado por instituições comunitárias e outras com as quais o serviço construa parcerias.

\section{Considerações finais}

Este trabalho pretendeu contribuir para uma reflexão conceitual de alargamento da noção de crise, entendida como uma problemática cruzada entre individualização e grupalização que, do ponto de vista da intervenção, evoca o trabalho psicossocial dos grupos e instituiçóes. Soma-se, ainda, a necessidade de se considerarem as determinaçōes socioculturais da adolescência para a estruturação dos serviços de saúde e de seus dispositivos de atenção.
Pensar a assistência ao adolescente em crise a partir dessas complexidades inclui, necessariamente, considerar a gestão dos serviços assistenciais, o que, a partir das reflexões aqui desenvolvidas, deve incluir não apenas as necessárias melhorias na administração de recursos, mas também o reconhecimento e fortalecimento de dispositivos dedicados às relações intersubjetivas.

Trata-se, portanto, de buscar outras formas de se fazer gestão em saúde. Nessa perspectiva, a gestão teria a função de oferecer certo suporte (KAËS, 2005) e de criar instâncias de análise para as equipes, entendendo que os dispositivos tradicionais de planejamento e gestão, como as reuniốes de equipe, os colegiados, também são espaços de articulação psicossocial (KAËS, 2003), de trânsito entre o eu e o grupo como conjunto intersubjetivo capaz de fomentar a compreensão dos processos de crise e de se constituir como espaço/setting que sustenta os momentos críticos de fragmentação, conflitos e tensão entre o que está instituído e a capacidade criativa e de invenção dos sujeitos.

\section{Referências}

AMARANTE, P. Saúde Mental e Atenção Psicossocial. Rio de Janeiro: Editora Fiocruz, 2007.

ARIĖS, P. História Social da Criança e da Família. 2. ed. Rio de Janeiro: Guanabara Koogan, 1981.

CAMPOS, R.O. Humano demasiado humano: un abordaje del malestar em la instituición hospitalaria. In: SPINELLI, H. (Org.)Salud Colectiva. Buenos Aires: Lugar Editorial, 2004, p.103-120.

SPINELLI, H. (Org.). Salud Colectiva. Buenos Aires: Lugar Editorial, 2004, p.103-120.

CARVALHO, I.S.; COSTA, I.I; BUCHER-MALUSCHKE, J.S.N.F. Psicose e Sociedade: interseções necessárias para a compreensão da crise. Revista Mal Estar e Subjetividade, Fortaleza, v.7, n. 1, p.163-189, 2007.

DELL'ACQUA, G.; MEZZINA, R. Resposta à crise. In: DELGADO, J. A loucura na sala de jantar. São Paulo: Resenha, 1991.

DIAZ, A.R.M. Pesquisa avaliativa em Saúde Mental: a regulação da "porta" nos Centros de Atenção Psicossocial. Dissertação (Mestrado em Saúde Coletiva) - Universidade Estadual de Campinas, São Paulo, 2009.

FERIGATTO, S.H,; CAMPOS, R.T.O; BALLARIN, M.L.G.S. O atendimento à crise em saúde mental: ampliando conceitos. Revista de Psicologia da UNESP, v.6, n.1, p. 31-44, 2007.

FIGUEIREDO, M.D.; CAMPOS, RO. Saúde Mental na atenção básica à saúde de Campinas, SP: uma rede ou um emaranhado? Ciência e Saúde Coletiva, v.14, n.1, p.129-138, 2009.

FRANÇA, I.G. Reflexões acerca da implantação e funcionamento de um plantão de emergência em saúde mental. Psicologia Ciência e Profissão, v.25, n.1, p.146-163, 2005.

KAËS R. Crisis, ruptura y superación: análisis transicional en psicoanálisis individual y grupal. Buenos Aires: Ediciones Cinco, 1982.

O interesse da Psicanálise para considerar a realidade psíquica da instituição. In: CORREA, O.B.R. Vínculos e Instituições: uma escuta psicanalítica. São Paulo: Escuta, 2002. P.11-32 
. Espaços Psíquicos Comuns e Partilhados. São Paulo: Casa do Psicólogo, 2005.

NAKAMURA, E. A noção médico-científica da depressão infantil: uma visão histórica esociocultural do discurso de adultos sobre a infância. In: MOTA, A.; SCHRAIBER, L. (Orgs). Infância e saúde: perspectivas históricas. São Paulo: Hucitec; FAPESP, 2009, p.234-264.

QUEIROZ, L.B. Da pediatria à saúde do adolescente: origens históricas de uma prática médica. In: MOTA, A.; SCHRAIBER, L. (Orgs). Infância e saúde: perspectivas históricas. São Paulo: Hucitec; FAPESP, 2009, p.265-283

TAKEUTI, N.M. No outro lado do espelho: a fratura social e as pulsões juvenis. Rio de Janeiro: Relume Dumará, 2002.
VASCONCELOS, E.M. Desafios Políticos da reforma psiquiátrica brasileira. São Paulo: Editora Hucitec, 2010.

VINCENTIN, C. Infância e adolescência: uma clínica necessariamente ampliada. Revista de Terapia Ocupacional da Universidade de São Paulo, São Paulo, v.17, n.1, abr. 2006.

Recebido para publicação em outubro de 2013

Versão final em dezembro de 2013

Conflito de interesse: não houve

suporte financeiro: inexistente 